NASA TECHNICAL NOTE

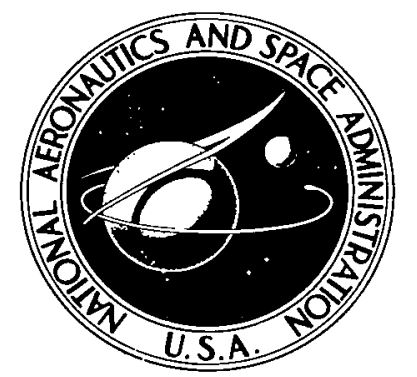

NASA IN D-5914

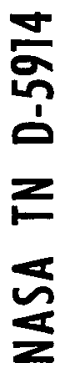

LOAN COPY: RETURN

AFWL (DOGL)

KIRTLAND AFB, N. I

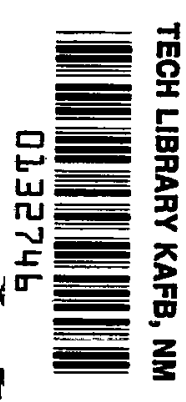

REDUCTION OF MUTUAL COUPLING USING PERFECTLY CONDUCTING FENCES

by $R \cdot J$ Mailloux

Electronics Research Center

Cambridge, Mass. 02139

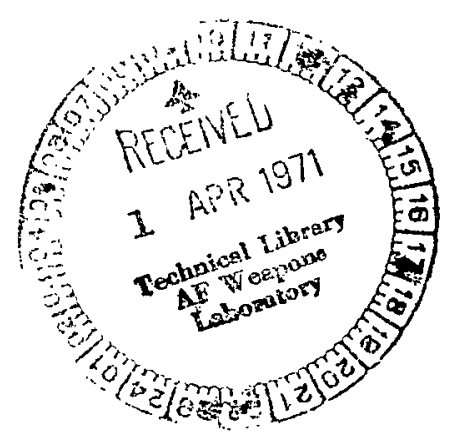

national aeronautics and SpaCe administration - washington, D. C. - March 1971 


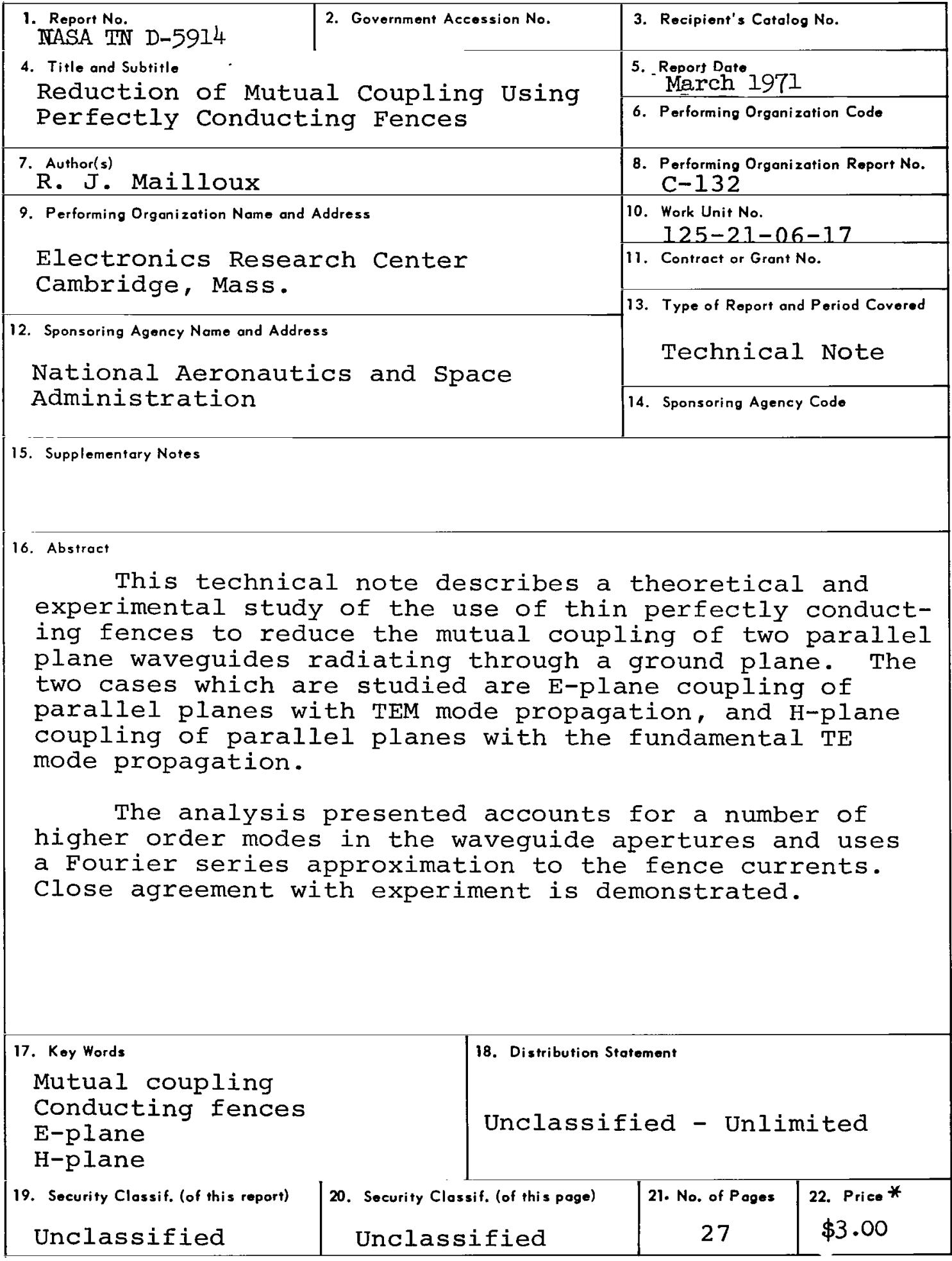

"For sale by the National Technical Information Service, Springfield, Virginia 22151 


\title{
REDUCTION OF MUTUAI COUPLING USING PERFECTLY CONDUCTING FENCES
}

\author{
By R. J. Mailloux \\ NASA/Electronics Research Center \\ Cambridge, Massachusetts
}

\section{SUMMARY}

This technical note describes a theoretical and experimental study of the use of thin perfectly conducting fences to reduce the mutual coupling of two parallel plane waveguides radiating through a ground plane. The two cases which are studied are E-plane coupling of parallel planes with TEM mode propagation, and $\mathrm{H}$-plane coupling of parallel planes with the fundamental TE mode propagation.

The analysis presented accounts for a number of higher order modes in the waveguide apertures and uses a Fourier series approximation to the fence currents. Close agreement with experiment is demonstrated.

\section{INTRODUCTION}

The adverse effects of mutual coupling between elements of phased array antennas have stimulated interest in methods of compensating for these effects (refs. 1-9). One of the oldest techniques for reducing mutual coupling between waveguide fed. slots (ref. 10) or dipole antennas (ref. 11) is the use of thin metallic fences perpendicular to the ground plane and located between the radiating elements. Studies of thin parallel planes extending beyond a ground plane and therefore in a fence-like arrangement have been performed by mode matching (ref. 12) for an infinite periodic structure and experimentaliy for a finite array (ref. 13).

This paper presents a theoretical and experimental study of E-plane and H-plane coupling between two parallel plane waveguides which radiate through a common ground plane. A conducting fence is placed half-way between the waveguides and the fence height is varied to determine its effect on coupled power. The analysis itself is rigorous within the limits of the mathematical model of a filimentary fence current and therefore implies the use of thin fences with rounded edges. Aside from this, the results themselves are approximate only because the series expressions for the aperture fields and fence current were truncated. A sufficient number of terms were taken to assure convergence of the coupled signal. 
The E-plane experimental results describe the coupling between flared horns, and are of interest because of the close similarities between the coupling of these structures and the parallel planes which are studied theoretically. Though agreement between theory and experiment is excellent, the horns were resistively loaded to eliminate moding effects and so are best interpreted as qualitative verification of the theory. To avoid this problem, the H-plane experiment was conducted in a parallel plane simulator. These results can be compared directly with the theory and once again the agreement is excellent.

The author thanks Mr. Ronald Levenson of Northeastern University and Mr. Ted Kelly of Service Technology Corporation for their help in performing the numerical computations, and Mr. F. J. LaRussa and C. L. Dunne for their work on the experimental phase of this study.

\section{MATHEMATICAL FORMULATION AND SOLUTIONS}

The analysis presented in this paper consists of writing the fields in the half space in terms of contributions from the electric field in each waveguide aperture and from the current induced in the conducting fence. A mode matching technique similar to that used by Mailloux (ref. 14) for rectangular waveguides and by $\mathrm{Wu}$ (ref. 15) for parallel planes is used to require field continuity at the apertures. In addition, the fence current is expanded in terms of a set of independent functions which satisfy the boundary conditions at the base and at the top of the fence. These expansions reduce the integral equations to sets of matrix equations which are solved in the general case using the method of symmetric components.

The basic geometries studied in this report are shown in Figure 1. Because of their two-dimensional nature the electromagnetic field for each of these problems can be expanded in terms of scalar Greens functions. The half space fields are written in terms of one component of the magnetic hertzian potential derived from the aperture fields and a single component of the vector potential derived from the fence current and its image (see Appendix A).

$$
\begin{aligned}
& \overline{\mathrm{B}}(\overline{\mathrm{r}})=\nabla \times \overline{\mathrm{A}}+\nabla\left(\nabla \cdot \overline{\mathrm{I}}_{\mathrm{m}}\right)+\mathrm{ko}^{2} \bar{\Pi}_{\mathrm{m}} \\
& \overline{\mathrm{E}}(\overline{\mathrm{r}})=-\mathrm{j} \overline{\mathrm{k}}^{2}\left[\nabla(\nabla \cdot \overline{\mathrm{A}})+\mathrm{k} \mathrm{o}^{2} \overline{\mathrm{A}}\right]-\mathrm{j} \omega \nabla \times \bar{\Pi} \mathrm{m}
\end{aligned}
$$

Only one component of vector potential $\bar{A}$ is present in each of these problems; that component is $\hat{z} A_{z}$ for the E-plane coupling 


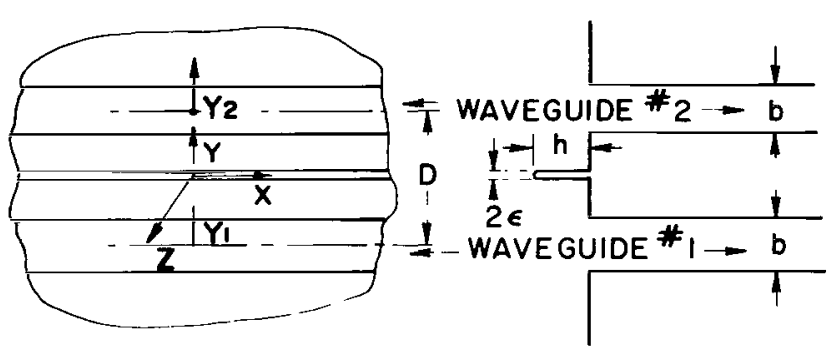

A. E-PLANE COUPLING



B. H-PLANE COUPLING

Figure 1.- Waveguide-fence geometries

problem (Figure $1 \mathrm{~A}$ ) and $\hat{\mathrm{Y} A} \mathrm{Y}$ for the $\mathrm{H}$-plane coupling problem (Figure 1B). The coordinate systems have been chosen so that the single component of magnetic Hertzion potential is $\hat{\mathrm{x}} \Pi \mathrm{m}_{\mathrm{x}}$ for both problems. Fields in the waveguides are derivable entirely in terms of the one component of magnetic potential and so are given by the above equations with $\bar{A} \equiv 0$. An exp $[+j \omega t)$ time dependence is assumed and has been suppressed.

\section{Case I - E-Plane Coupling}

Figure IA shows the basic geometry for the E-plane coupling problem. It is assumed that TEM fields are incident from one or both waveguides and therefore that $\partial / \partial x=0$. The field in each waveguide $(p)$ is given in terms of the magnetic hertzian potentials.

$\Pi m x_{p}\left(y_{p}, z\right)=B_{p}\left(e^{-j k o z}-\Gamma_{p} e^{+j k o z}\right)+\sum_{n=1}^{\infty} A n_{p} \cos \left[\frac{n \pi}{b}\left(y_{p}+b / 2\right)\right] e^{\alpha n^{z}}$ 
where

$$
\begin{aligned}
\alpha_{n} & =\sqrt{\left(\frac{n \pi}{b}\right)^{2}-k o^{2}} \text { for }\left(\frac{n \pi}{b}\right)^{2}>k o^{2} \\
& =j \sqrt{k o^{2}-\left(\frac{n \pi}{b}\right)^{2}} \text { for } \mathrm{ko}^{2}>\left(\frac{n \pi}{b}\right)^{2}
\end{aligned}
$$

This expression includes all of the propagating and nonpropagating higher order modes. In many of the cases considered the dimension $\mathrm{b}<\frac{\lambda}{2}$, therefore all of the higher order modes are non-propagating, but one higher order mode $(n=1)$ is allowed to propagate in one of the cases which was verified experimentally.

In the external space $(z>0)$ the magnetic Hertzian potential, the vector potential and the electromagnetic fields are given by:

$$
\begin{aligned}
& \operatorname{Im} x^{\prime}(y, z)=\frac{-1}{2 \omega}\left\{\int_{-b / 2}^{b / 2} d y_{1}^{\prime} E_{1}\left(y_{l}^{\prime}\right) \text { Hо }{ }^{(2)}\left(k \circ \sqrt{z^{2}+\left(y-y_{1}^{\prime}+D / 2\right)^{2}}\right)\right. \\
& +\int_{-b / 2}^{b / 2} d y_{2}^{\prime} E y_{2}\left(y_{2}^{\prime}\right) \text { Ho }{ }^{(2)}\left(k \circ \sqrt{\left.z^{2}+\left(y-y_{2}^{\prime}\right)-D / 2\right)^{2}}\right\} \\
& A z(y, z)=\frac{-j}{2 v_{0}} \int_{0}^{h} d z^{\prime} \operatorname{Iz}\left(z^{\prime}\right)\left[H _ { 0 } ^ { ( 2 ) } \left(k \circ \sqrt{\left(z-z^{\prime}\right)^{2}+y^{2}}\right.\right. \\
& +\mathrm{HO}^{(2)}\left(\mathrm{kO} \sqrt{\left.\left.\left(\mathrm{z}+\mathrm{z}^{\prime}\right)^{2}+\mathrm{y}^{2}\right)\right]}\right. \\
& E x=B y=B z=0 \quad E y=-\frac{j \omega}{k O}{ }^{2} \frac{\partial^{2} A z}{\partial y^{\partial} z}-\frac{j \omega \partial \Pi^{\prime} m x}{\partial z} \\
& E z=-\frac{j \omega}{k \circ} 2\left(\frac{\partial^{2} A z}{\partial z^{2}}+k O^{2} A z\right)+j \omega \frac{\partial \Pi \cdot m x}{\partial y} \quad B x=\frac{\partial A z}{\partial y}+k O^{2} \Pi{ }^{\prime} m x
\end{aligned}
$$

where Ho ${ }^{(2)}(x)$ is the Hankel function of zero order and of the second kind.

In addition, $\frac{1}{v_{0}}=\mu 0=4 \pi \times 10^{-7}$ henry/meter and all parameters are given in terms of MKS practical units.

The aperture electric field which is used in Eq. (3) is derived from the magnetic potential inside the waveguides Eq. (2) 
at $\mathbf{z}=0$. The fence current used in Eq. (4) is assumed to be concentrated at the center of the fence and to flow entirely in the $\hat{z}$ direction. This is consistent with the assumption of a thin fence with the top edge rounded to form a semi-cylinder.

Equating the tangential electric field (Ez) to zero along the fence yields the integrodifferential equations (at $y= \pm \varepsilon$ and $z=0$ to $h$ ).

$$
\left(\frac{\partial^{2}}{\partial^{2}}+k o^{2}\right) A z(y, z)=k o^{2} \frac{\partial \Pi m^{\prime} x}{\partial y}(y, z)
$$

Because the fence is thin compared to any of the characteristic dimensions of the problem, including wavelength, these two equations are nearly identical and only the equation at $y=+\varepsilon$ need be considered. This is equivalent to the assumption that the fence is sufficiently thin that with the two waveguides driven antisymmetrically one could insert or remove the fence without changing the fields.

This equation has a solution in the form of an integral equation.

$A z(\varepsilon, z)=A \operatorname{coskoz}+B \operatorname{sinkoz}+k o \int_{0}^{z} \frac{\partial \Pi m x^{\prime}}{\partial y}(\varepsilon, \beta)$ sinko $(z-\beta) d \beta$

The constant $B$ is zero because of the boundary condition Ey=0 at $z=0$. The constant $A$ is required so that the current be set equal to zero at the top of the fence.

Continuity of the tangential electric field is assured because of the nature of the Greens functions, and continuity of the tangential magnetic field $(\mathrm{Bx})$ results in the integral equation below.

At each aperture $\left(-\frac{b}{2} \leq y_{p} \leq b / 2\right)$

$$
k o^{2} \operatorname{Imx}(y, 0)=\mathrm{ko}^{2} \operatorname{Im} \mathrm{x}^{\prime}(\mathrm{y}, \mathrm{O})+\frac{\partial \mathrm{Ay}}{\partial \mathrm{y}}(\mathrm{y}, \mathrm{o})
$$

This formulation has therefore resulted in a set of three coupled integral equations which describe the general problem of two parallel plane waveguides radiating through a common ground plane and with a perfectly conducting fence between the two guides. 


\section{SOLUTION BY THE METHOD OF SYMMETRIC COMPONENTS}

Since the geometry of the fence and apertures is symmetric about $y=0$, the general coupling problem can be formulated in terms of the solution to the problems of coupling under symmetric and antisymmetric incident fields. The incident fields will be normalized to unity and therefore the symmetric excitation case is defined by the situation wherein both waveguides are driven with equal and opposite incident fields $\mathrm{BS}=1=\mathrm{B}_{1}=-\mathrm{B}_{2}$ and the antisymmetric case is defined by $\mathrm{BA}=1=\mathrm{B}_{1}=\mathrm{B}_{2}$. The resulting aperture equations reduce to a single equation for each of these conditions using the following relations: for the symmetric case $A n_{1}=-(-I) n_{A n} \equiv A n s$ and $\Gamma_{1}=\Gamma_{2}=\Gamma s$, and for the antisymmetric case $\mathrm{An}_{1}=(-1) \mathrm{nAn}_{2} \equiv \mathrm{An} \overline{\mathrm{A}}$ and ${ }^{2} \Gamma_{1}=\Gamma_{2}=\Gamma^{\mathrm{A}}$. With these definitions the fence current is zero for the case of the antisymmetric equation, and since the fence is thin its presence does not disturb the field. Therefore, only the single aperture equation remains for the antisymmetric condition. Fence and aperture equations remain coupled for the symmetric excitation case, but again because of symmetry only one aperture equation (in addition to the fence equation) is necessary.

In order to arrive at a set of equations normalized to the incident wave of the Hertzian potential, the fence current is written in terms of the parameter $C_{z} f(z)$ according to the following definition:

$$
I_{z}(z)=i 2 v_{o} k_{o}^{2} C_{z} f(z)
$$

Ey is zero at $z=0$ and so the $z$-derivative of the current is zero at that point. Since the current is zero at $z=h$ it is therefore written as a truncated Fourier series of cosine functions.

$$
\mathrm{C}_{z} f(z)=\underbrace{\mathrm{M}_{\mathrm{T}}}_{\mathrm{m}=1} \quad \mathrm{C}_{\mathrm{m}} \mathrm{f}_{\mathrm{m}}(\mathrm{z})
$$

where

$$
f_{m}(z)=\cos \left[\frac{(2 m-1)}{2 h}\right] \pi z
$$

In the case of a fence with zero thickness, the $z$-derivative of the current is infinite at $z=h$, but for the fence model used here the charge remains finite though large. 
Using this expression for the fence current, and after defining the integrals below, the equations for symmetric and antisymmetric excitation may be written in a simple algebraic fashion.

$$
\begin{aligned}
& \text { In }(y)=\int_{-b / 2}^{b / 2} d y^{\prime} \cos \frac{n \pi}{b}\left(y^{\prime}+b / 2\right) H_{o}^{(2)}\left(k_{o}\left|y-y^{\prime}\right|\right) \\
& B(m)=\int_{0}^{z} d z^{\prime} f_{m}\left(z^{\prime}\right)\left[\frac{2 y^{H}{ }^{(2)}\left(k_{o} \sqrt{\left.\left(z^{\prime}\right)^{2}+y^{2}\right)}\right.}{k_{o} \sqrt{\left(z^{\prime}\right)^{2}+y^{2}}}\right] \\
& a(m)=\int_{0}^{h} d z^{\prime} f_{m}\left(z^{\prime}\right)\left[H _ { 0 } ( 2 ) \left(k_{0} \sqrt{\left.\left(z-z^{\prime}\right)^{2}+\varepsilon^{2}\right)}\right.\right. \\
& +\mathrm{H}_{\mathrm{O}}^{(2)}\left(\mathrm{k}_{\mathrm{O}} \sqrt{\left.\left(z+z^{\prime}\right)^{2}+\varepsilon^{2}\right)}\right] \\
& f_{n}(z)=\int_{-b / 2}^{b / 2} d y^{\prime} \cos \frac{n \pi}{b}\left(y^{\prime}+b / 2\right) \int_{0}^{z} d z^{\prime} \sin k_{0}\left(z-z^{\prime}\right)
\end{aligned}
$$

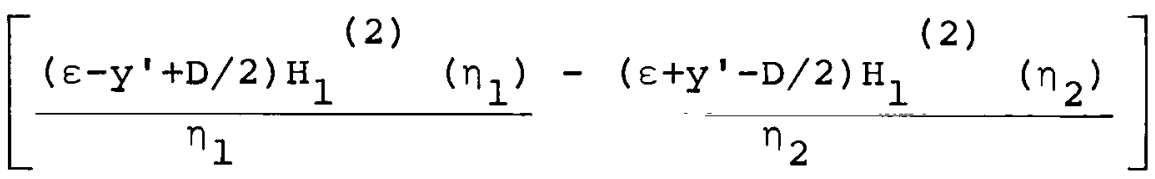

where

$$
\begin{aligned}
& n_{1}=k_{0} \sqrt{\left(z^{\prime}\right)^{2}+\left(\varepsilon-y^{\prime}+D / 2\right)^{2}} \\
& n_{2}=k_{0} \sqrt{\left(z^{\prime}\right)^{2}+\left(\varepsilon+y^{\prime}-D / 2\right)^{2}}
\end{aligned}
$$

and $\mathrm{H}_{1}{ }^{(2)}$ is the Hankel function of the second kind of order 1 . 
Symmetric Aperture Equation:

$$
\begin{aligned}
& 1-\frac{k_{o}}{2} I_{0}(y)+\frac{k_{o}}{2} I_{0}(D-y)=\Gamma^{S}\left[I+\frac{k_{0}}{2} I_{0}(y)-\frac{k_{0}}{2} I_{0}(D-y)\right] \\
& +\sum_{n=1}^{N_{T}} A_{n} S\left[-\cos \frac{n \pi}{b}\left(y^{\prime}+b / 2\right)+\frac{j}{2} \alpha_{n} I_{n}(y)-\frac{j}{2} \alpha_{n} I_{n}(D-y)\right] \\
& -k_{0}^{2} \sum_{m=1}^{M_{T}} C_{m} B_{m}(m)
\end{aligned}
$$

Symmetric Fence Equation:

$$
\begin{gathered}
-k_{0}{ }^{3} f_{0}(z)=k_{0}{ }^{3} f_{0}(z) \Gamma+j k_{0}{ }^{2} \sum_{n=1}^{N_{T}} \alpha_{n} f_{n}(z) A_{n} S \\
-2 A k_{\circ} \cos k_{0} z+2 k_{\circ} \sum_{m=1}^{M_{T}} C_{m} a(m)
\end{gathered}
$$

Antisymmetric Aperture Equation:

$$
\begin{aligned}
I & -\frac{k_{O}}{2} I_{0}(y)-\frac{k_{O}}{2} I_{0}(D-y)=\Gamma^{A}\left[I+\frac{k_{O}}{2} I_{0}(y)+\frac{k_{O}}{2} I_{0}(D-y)\right] \\
& +\sum_{n=1}^{N_{t}} A_{n}{ }^{A}\left[-\cos \frac{n \pi}{b}(y+b / 2)+\frac{j}{2} \alpha_{n} I_{n}(y)+\frac{j}{2} I_{n}(D-y)\right]^{(14)}
\end{aligned}
$$

In this form the equations are dimensionless. There are a total of $\mathrm{M}_{t}+\mathrm{N}_{t}+2$ unknowns for the case of symmetric excitation, where $N_{t}$ is the upper limit of the terms actually used to represent the waveguide fields. The antisymmetric aperture equation is not coupled to the fence equation and therefore has only $\mathrm{N}_{t}+1$ unknowns. Both sets of equations are solved by requiring them to be satisfied at $\mathrm{N}_{t}+1$ equally spaced points in the aperture (including 
$y= \pm b / 2)$; and for the symmetric excitation case the fence equation is required to be satisfied at $M_{t}+1$ evenly spaced points on the fence (including $z=0$ and $h$ ).

The solution for this waveguide-fence problem for the case of arbitrary excitation $\left(B_{Z} \neq B_{1} \neq 1\right)$ can be solved in terms of the solution presented here. To accomplish this, one merely multiplies the symmetric and antisymmetric solutions by appropriate constants in order to match the incident signals. All boundary conditions remain satisfied and so the general solution is found by multiplying the symmetric and antisymmetric solutions by the same constants and adding the results.

The most important case to consider is that of an incident wave of amplitude unity in waveguide 1 and with waveguide 2 terminated in a matched load. This case is important because the results are the coefficients of the network scattering matrix and are the most conveniently measured parameters of the coupled waveguide problem. These incident conditions are matched by taking $\mathrm{B}_{1}=1=\mathrm{BS}+\mathrm{B}^{\mathrm{A}}$ in Waveguide 1 and $\mathrm{B}_{2}=0=-\mathrm{BS}+\mathrm{BA}$ in Waveguide 2. Taking $\mathrm{B}^{\mathrm{S}}=\mathrm{B}^{\mathrm{A}}=1 / 2$ and summing these two solutions completes the solution for this parasitic case. The coeffieient of the wave propagatingtin the negative $z$ direction in Waveguide 1 is therefore the reflection coefficient. (Sll) of this waveguide and in Waveguide 2 , it is the transmission coefficient through the two port network $\left(S_{12}\right)$. According to the superposition principle described earlier, the complete solution to this parasitic problem is given below.

$$
\begin{array}{ll}
\Gamma_{1}^{P}=S_{11}=1 / 2\left(\Gamma^{S}+\Gamma^{A}\right) & \Gamma_{2}^{P}=S_{12}=1 / 2\left(-\Gamma^{S}+\Gamma^{A}\right) \\
A_{n}{ }^{P}=1 / 2\left(A_{n}^{2}+A_{n}^{A}\right) & A_{n_{2}}{ }^{A}=(1 / 2)(-1)^{n}\left(-A_{n}^{S}+A_{n}^{A}\right) \\
\text { and } C_{n}{ }^{P}=1 / 2 C_{n}
\end{array}
$$

Because of symmetry and reciprocity, the remaining coefficients of the two-port scattering matrix are obtained directly using $\mathrm{S}_{22}=\mathrm{S}_{11}$ and $\mathrm{S}_{21}=\mathrm{S}_{12}$. The input admittance for this parasitic case is $y_{11}=\frac{1-s_{11}}{1+s_{11}}$, and the power coupled into waveguide 2 is $20 \log \mathrm{S}_{12}$, in decibels with respect to the incident power in Waveguide 1. These parameters are of prime importance throughout this paper. 


\section{Case II - H-Plane Coupling}

Figure IB shows the basic geometry for the H-plane coupling problem. It is assumed that the lowest order (dominant) TE mode field is incident from the parallel plane waveguide, and therefore that $\partial / \partial y=0$. This symmetry is maintained by the aperture and fence geometry and so the entire field is independent of the coordinate $y$.

The field in each waveguide is therefore given in terms of the magnetic Hertzian potential:

$$
\begin{aligned}
I_{m p} x_{p}\left(x_{p}, z\right) & =B_{p}\left(e^{-j \beta z}-\Gamma e^{+j \beta z}\right) \sin \left[\frac{\pi\left(x_{p}+a / 2\right)}{a}\right] \\
& +\sum_{m=2}^{\infty} A_{m p} \sin \left[\frac{m \pi}{a}\left(x_{p}+a / 2\right)\right] e^{\alpha_{m} z}
\end{aligned}
$$

where

$$
\beta=\sqrt{k_{o}^{2}-\left(\frac{\pi}{a}\right)^{2}}
$$

and

$$
\alpha_{m}=\sqrt{\left(\frac{m \pi}{a}\right)^{2}-k_{o}^{2}} \text { for } m>1
$$

It is assumed that all higher order modes are attenuating; this is true for the range of $a / \lambda$ chosen, $1 / 2<a / \lambda<1$. Since $\partial / \partial y \equiv 0$, and given the existing symmetries, the only non-zero field components are $\mathrm{B}_{\mathrm{X}}, \mathrm{B}_{\mathrm{z}}$ and $\mathrm{E}_{\mathrm{y}}$. Using the same assumptions as before for this electromagnetic model of a thin fence, one obtains the half-space fields derived from the potential functions below.

$$
\begin{aligned}
\Pi_{m^{\prime} x(x, z)} & =\frac{-1}{2 w}\left[\int _ { - a / 2 } ^ { a / 2 } d x _ { 1 } ^ { \prime } E _ { 1 } ^ { \prime } ( x _ { 1 } ^ { \prime } ) H _ { 0 } ^ { ( 2 ) } \left(k_{0} \sqrt{z^{2}+\left(x-x_{1}^{\prime}+D / 2\right)^{2}}\right.\right. \\
& +\int_{-a / 2}^{a / 2} d x_{2}^{\prime} E_{y_{2}}\left(x_{2}^{\prime}\right) H_{0}(2)\left(k_{0} \sqrt{\left.z^{2}+\left(x_{-} x_{2}^{\prime}-D / 2\right)^{2}\right)}\right]
\end{aligned}
$$




$$
\begin{aligned}
& A_{Y}(x, z)=\frac{-i}{2 \omega} \int_{0}^{h} d z^{\prime} I_{Y}\left(z^{\prime}\right)\left[H _ { 0 } ( 2 ) \left(k_{0} \sqrt{\left.\left(z-z^{\prime}\right)^{2}+x^{2}\right)}\right.\right. \\
& -H_{0}^{(2)}\left(k_{0} \sqrt{\left.\left(z+z^{\prime}\right)^{2}+x^{2}\right)}\right] \\
& E_{x}=E_{z}=B_{y}=0 \\
& B_{z}=\frac{\partial^{2} \Pi m x^{\prime}}{\partial x \partial z} \frac{\partial A}{\partial x} \quad B_{x}=\frac{\partial^{2} \Pi_{m} x^{\prime}}{\partial x^{2}}+k_{0}{ }^{2} \Pi_{m} x^{\prime}-\frac{\partial A}{\partial z} \\
& E_{y}=\frac{-j \omega \partial I_{m} x^{\prime}}{\partial z}-j \omega A_{Y}
\end{aligned}
$$

The aperture field to be used in Eq. (17) is derived from the magnetic potential inside the waveguides (Eq. 16) at $z=0$. Equating the tangential electric field $\left(\mathrm{E}_{\mathrm{y}}\right)$ to zero along the fence at $\mathrm{x}=\varepsilon$ yields the following integral equation.

$$
A_{y}(\varepsilon, z)=\frac{-\partial \Pi \cdot{ }^{\prime} x(\varepsilon, z)}{\partial z}
$$

Again requiring continuity of the tangential B fields at the aperture yields the integrodifferential equation (evaluated at $\mathbf{z}=0$ ).

$$
\left({\frac{\partial^{2}}{\partial x_{p}^{2}}}^{2} k_{o}^{2}\right) \Pi_{m} x_{p}\left(x_{p}\right)=\left({\frac{\partial^{2}}{\partial x_{p}^{2}}}^{+k_{o}^{2}}\right) \Pi_{m}^{\prime} x_{p}\left(x_{p}\right)-\frac{\partial A y\left(x_{p}\right)}{\partial z}
$$

A particular integral can be found for this equation which results in the general solution below; itself an integral equation.

$$
\begin{aligned}
\Pi_{m} x_{p}\left(x_{p}\right) & \left.=\pi_{m^{\prime}} x_{p}\right)+k_{2 p-1} \cos k_{o} x_{p} \\
& +k_{2 p} \sin k_{o} x_{p}-\frac{1}{k_{0}} \int_{0}^{x_{p}} \frac{\partial A_{y}}{\partial z}\left(x_{p}^{\prime}, z\right) \sin k_{o}\left(x_{p}-x_{p}^{\prime}\right) d x_{p}^{\prime}
\end{aligned}
$$


Both constants $K_{2 p}$ and $K_{2 p-1}$ are needed at each aperture in order to assure that singularities at the edges $x_{p}= \pm a / 2$ are integrable. This formulation has therefore resulted in a set of three coupled integral equations which describe the general problem of two parallel plane waveguides with incident $\mathrm{TE}_{10}$ modes radiating through a ground plane and with a perfectly conducting fence between the guides.

As for the E-plane coupling problem, one can formulate the case of H-plane coupling with arbitrary incident fields in terms of the solutions of coupling under symmetric and antisymmetric incident fields. The symmetric case is defined by the situation wherein both waveguides are driven with equal incident fields $\mathrm{B}^{\mathrm{S}}=1=\mathrm{B}_{1}=\mathrm{B}_{2}$ and in the antisymmetric case by equal and opposite incident fields $\mathrm{BA}=1=\mathrm{B}_{1}=-\mathrm{B}_{2}$. The resulting aperture equations reduce to a single equation for each of these conditions using the following relations: for the summetric case: $\mathrm{A}_{\mathrm{m}}^{\mathrm{S}}=\mathrm{A}_{\mathrm{ml}}=-(-1) \mathrm{m}_{\mathrm{A} 2}, \mathrm{~K}_{1}^{\mathrm{S}}=\mathrm{K}_{1}=\mathrm{K}_{3}, \mathrm{~K}_{2}^{\mathrm{S}}=\mathrm{K}_{2}=\mathrm{K}_{5}$ and $\Gamma^{\mathrm{s}}=\Gamma^{1}=\Gamma^{2}$, and for the antisymmetric case: $\mathrm{A}_{\mathrm{m}}^{\mathrm{A}}={ }^{2} \mathrm{~A}_{\mathrm{ml}}=(-1) \mathrm{m}_{\mathrm{A}_{\mathrm{m} 2}}, \mathrm{~K}_{1}^{\mathrm{A}}=\mathrm{K}_{1}$ $=-\mathrm{K}_{3}, \mathrm{~K}_{2}^{\mathrm{A}}=\mathrm{K}_{2}=-\mathrm{K}_{5}$ and $\Gamma^{\mathrm{A}}=\Gamma^{1}=\Gamma^{2}$. The fence current is zero for the antisymmetric case and the fence equation is neglected for this case. This procedure has reduced the set of three simultaneous integral equations to a pair of simultaneous integral equations for the symmetric case and a single integral equation for the antisymmetric case.

The normalization of $\mathrm{B}^{\mathrm{S}}$ and $\mathrm{B}^{\mathrm{A}}$ to unity is carried through to the fence current by defining $C_{Y} f(z)$ in a manner equivalent to $\mathrm{Eq} .9$.

This current is here written as a truncated Fourier series of sine functions in the $\hat{z}$ co-ordinate because the current is zero at $z=0$. It flows in the $\hat{y}$ direction and so is not zero at the edge of the fence $(z=h)$. In the case of a zero thickness fence this current is singular at $z=h$, but for the finite thicknesses with cylindrical top studied here the current remains finite though large.

$$
C_{Y} E(z)=\sum_{n=1}^{N_{T}} C_{n} f_{n}(z)
$$

where $f_{n}(z)=\sin \left[(2 n-I) \frac{\pi z}{2 h}\right]$

The integral equations are re-cast using the following definitions for numerical purposes. 
$I_{m}(x)=\int_{-a / 2}^{a / 2} \sin \left[\frac{m \pi}{a}\left(x^{\prime}+a / 2\right)\right] H_{0}^{(2)}\left(k_{0}\left|x-x^{\prime}\right|\right) d x^{\prime}$

$G n(x)=-2 k_{0}^{2} \int_{-a / 2}^{x} d x^{\prime} \sin k_{0}\left(x-x^{\prime}\right)$

$$
\int_{0}^{h} d z^{\prime}\left(f_{n}\left(z^{\prime}\right)\right) z^{\prime} H_{1}^{(2)} \frac{\left[k o \sqrt{\left(z^{\prime}\right)^{2}+\left(x^{\prime}-D / 2\right)^{2}}\right]}{\sqrt{\left(z^{\prime}\right)^{2}+\left(x^{\prime}-D / 2\right)^{2}}}
$$

$\gamma_{m}(x, z)=\int_{-a / 2}^{a / 2} d x^{\prime}\left(\sin \frac{m \pi}{a}\left(x^{\prime}+a / 2\right)\right) z_{1}^{(2)} \frac{\left(k_{0} \sqrt{z^{2}+\left(\varepsilon-x^{\prime}+D / 2\right)^{2}}\right)}{\left.k_{0} \sqrt{z^{2}+\left(\varepsilon-x^{\prime}+D / 2\right.}\right)^{2}}$

$F_{n}(z)=\int_{0}^{h} d z^{\prime}\left(f_{n}\left(z^{\prime}\right)\right)\left[H_{0}^{(2)}\left(k_{0} \sqrt{\left.\left(z-z^{\prime}\right)^{2}+\varepsilon^{2}\right)}\right.\right.$

$$
-H_{O}^{(2)}\left(k_{0} \sqrt{\left.\left(z+z^{\prime}\right)^{2}+\varepsilon^{2}\right)}\right]
$$

With these definitions, one may re-write the symmetric and antisymmetric equations as:

Symmetric Aperture Equation:

$$
\begin{aligned}
\sin \frac{\pi}{a}(x+a / 2) & -(1 / 2) B I_{1}(x)-(1 / 2) B I_{1}(D-x)=\Gamma^{S}\left[\sin \left[\frac{\pi}{a}(x+a / 2)\right]+(1 / 2) B I_{1}(x)+(1 / 2) B I_{1}(D-x)\right] \\
& +\sum_{m=2}^{M_{t}} A_{m}^{S}\left[-\sin \left(\frac{m \pi}{a}(x+a / 2)\right)+\frac{j \alpha_{m} I_{m}}{2}(x)+\frac{j \alpha_{m}}{2} I_{m}(D-x)\right] \\
& +C_{1}^{s} \cos k_{o} x+C_{2}^{S} \sin k_{o} x+\sum_{n=1}^{N_{t}} C_{n} G_{n}(x)
\end{aligned}
$$


Symmetric Fence Equation:

$$
\beta \gamma_{I}(z)=-\beta \Gamma^{s} \gamma_{I}(z)-j \sum_{m=2}^{M_{t}} \alpha_{m}{ }_{m}^{s_{m}} \gamma_{m}(z)+\sum_{n=1}^{N_{t}} C_{n} F_{n}(z)
$$

Antisymmetric Aperture Equation:

$$
\begin{aligned}
\sin \left(\frac{\pi}{a}(x+a / 2)\right)- & (1 / 2) B I_{1}(x)+(1 / 2) \beta I_{1}(D-x)=\Gamma^{A}\left[\sin \left(\frac{\pi}{a}(x+a / 2)\right)+(1 / 2) \beta I_{1}(x)-(1 / 2) B I_{1}(D-x)\right] \\
& +\sum_{m=2}^{M_{t}} A_{m}^{A}\left[-\sin \left[\frac{m \pi}{a}(x+a / 2)\right]+\frac{j \alpha_{m} I_{m}}{2}(x)-\frac{j \alpha_{m} I_{m}}{2}(D-x)\right]+C_{1}^{A} \cos k_{0} x+C_{2}^{A} \sin k_{0} x
\end{aligned}
$$

The equations are dimensionless. There is a total of $M_{t}+N_{t}+2$ unknowns for the case of symmetric equation ( $M_{t}$ is the total number of terms used to represent the aperture fields). The antisymmetric aperture equation is not coupled to the fence equation and so has only $M_{t}+2$ unknowns. Both sets of equations are required to be satisfied at $M_{t}+2$ equally spaced points in the aperture, including $\mathrm{x}= \pm \mathrm{a} / 2 ;$ and for the symmetric case the fence equation is also required to be satisfied at $\mathrm{N}_{t}$ evenly spaced points on the fence, excluding $z=0$.

As for the E-plane, the solution for the case of arbitrary excitation may be obtained from the symmetric and antisymmetric solutions. The solution for an incident wave of amplitude unity in waveguide 1 and waveguide 2 terminated in a matched load is obtained by setting $B_{1}=1=B^{A}$ in waveguide 2 . Taking $B^{S}=B^{A}$ $=1 / 2$ and summing the two solutions gives the solution for this parasitic case which leads to the same expressions as in equation 15 for the mode coefficients in waveguide 1 for the E-plane case, and the coefficients $\Gamma \frac{\mathrm{p}}{2}$ and $\mathrm{A} \mathrm{p}_{2}$ are the negative of those of Eq. 15 .

\section{Theoretical and Experimental Results}

E-Plane Case.- An experiment was conducted to verify the analytical results. H-plane flared horns were used to approximate the coupled parallel planes, and because the horn "B" dimension was large enough to support a higher order mode, an attenuating vane was inserted in the center of each horn parallel to the Hplane and across the entire horn. This vane was found to attenuate the fundamental mode horn transmission by $3.7 \mathrm{~dB}$, and it effectively eliminated all difficulties with propagation of the higher 
order mode. This $3.7 \mathrm{~dB}$ correction was applied to all experimental data of Figure 2. The horn length was $83 / 4 "$ and the aperture H-plane and E-plane dimensions were 5.0" and 0.790". The effects of reflections were partially removed from the measured data by scanning the frequency and averaging the coupling measurement at the frequency of concern. The data of Figure 2 was recorded at $90 \mathrm{GHz}$.

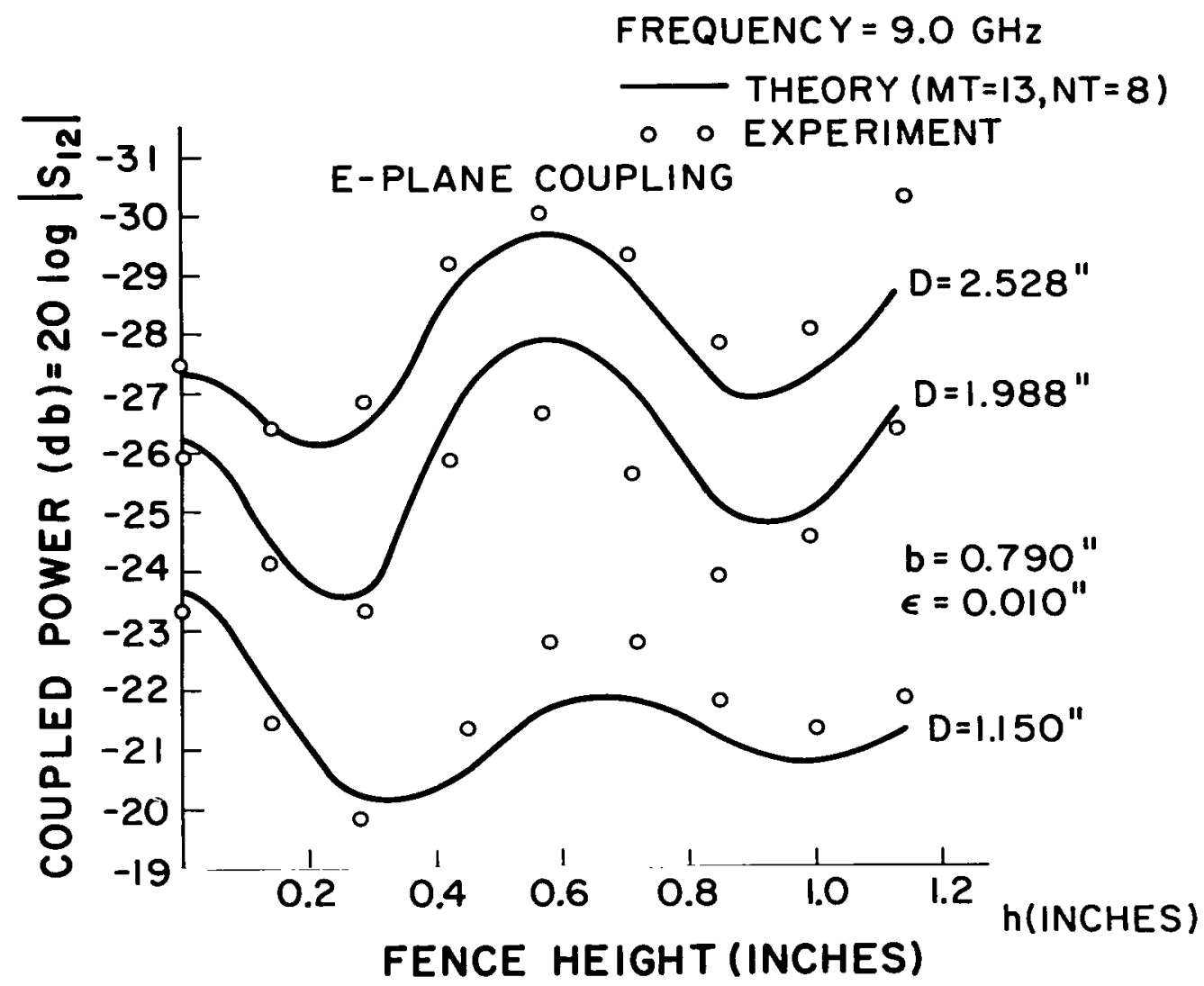

Figure 2.- Experimental and theoretical results for E-plane coupling $(b / \lambda=0.6)$

This data shows surprisingly good correlation between theory and experiment, and indicates that for the case of E-plane coupling even these relatively small horns are a good approximation to the parallel plane case. Of particular interest on this curve is the fact that the coupling actually increases for short fence heights. This same result is evident in the theoretical data of Figure 3 . Figure 4 shows the normalized theoretical fence current distribution for fences of various height. It is clear that this distribution becomes very complex for fence heights in excess of 
$0.3 \lambda$. Figure 5 shows the coupled power for the case of much narrower parallel plane apertures. The solution is fundamentally quite different for this situation from that of Figure 3 , and the metallic fence can bring about a significant reduction in coupling for some plane separations. Figure 6 shows the fence current distribution for various fence heights and with $\mathrm{b} / \lambda=0.2$ and $\mathrm{D} / \lambda=0.25$. It is noteworthy that the current distributions for the larger $h / \lambda$ values are very different from those of Figure 4 for the case of much wider slot separation. In each of these cases the number of terms in the Fourier series expressions was tested for convergence of both the coupling and the fence current distribution. The values $\mathrm{M}_{\mathrm{T}}=13, \mathrm{~N}_{\mathrm{T}}=8$, were used for the figures and appear to guarantee convergence to within the reading accuracy of these curves.

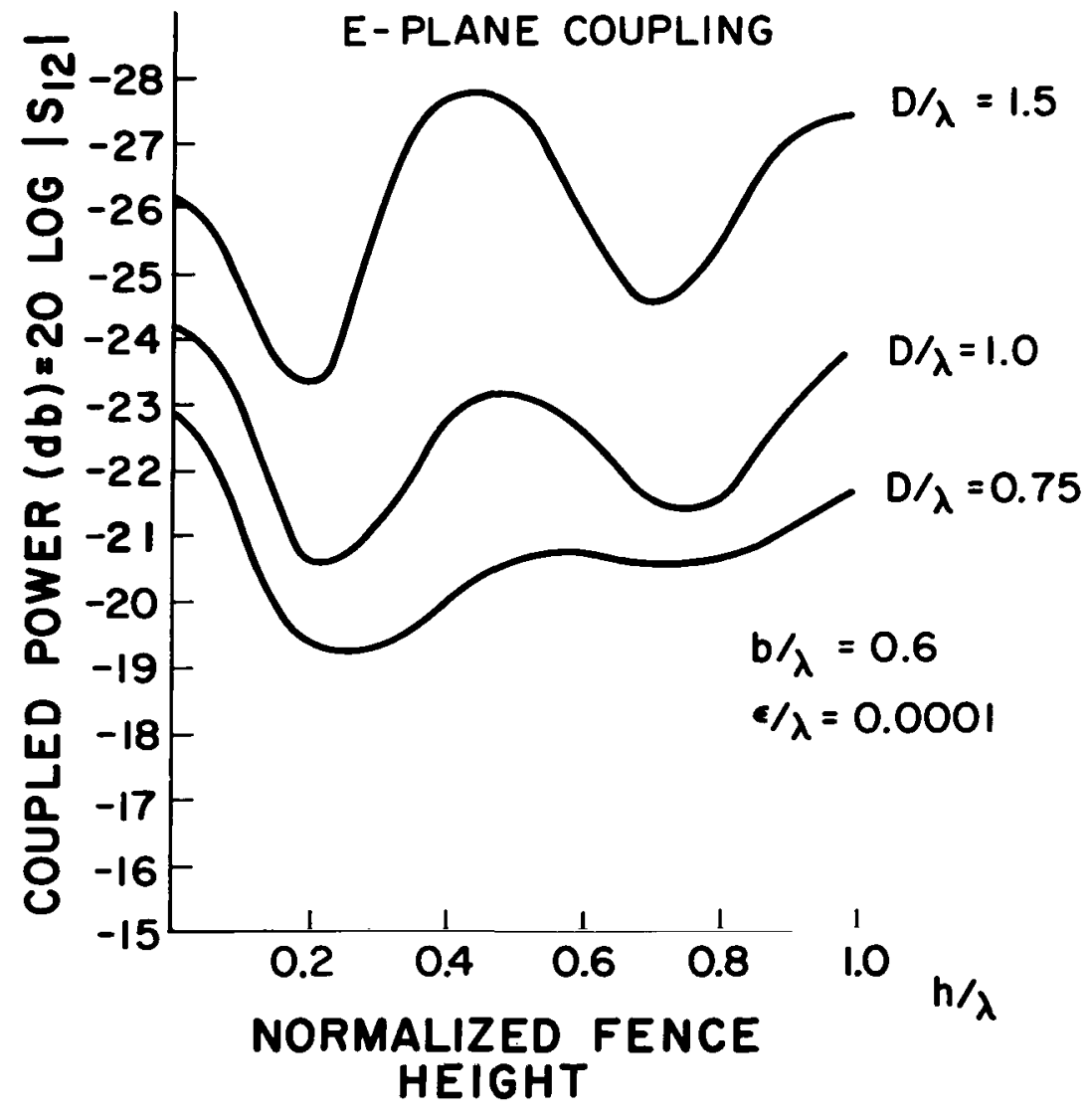

Figure 3.- Theoretical coupled power for E-plane coupling $(b / \lambda=0.6)$ 


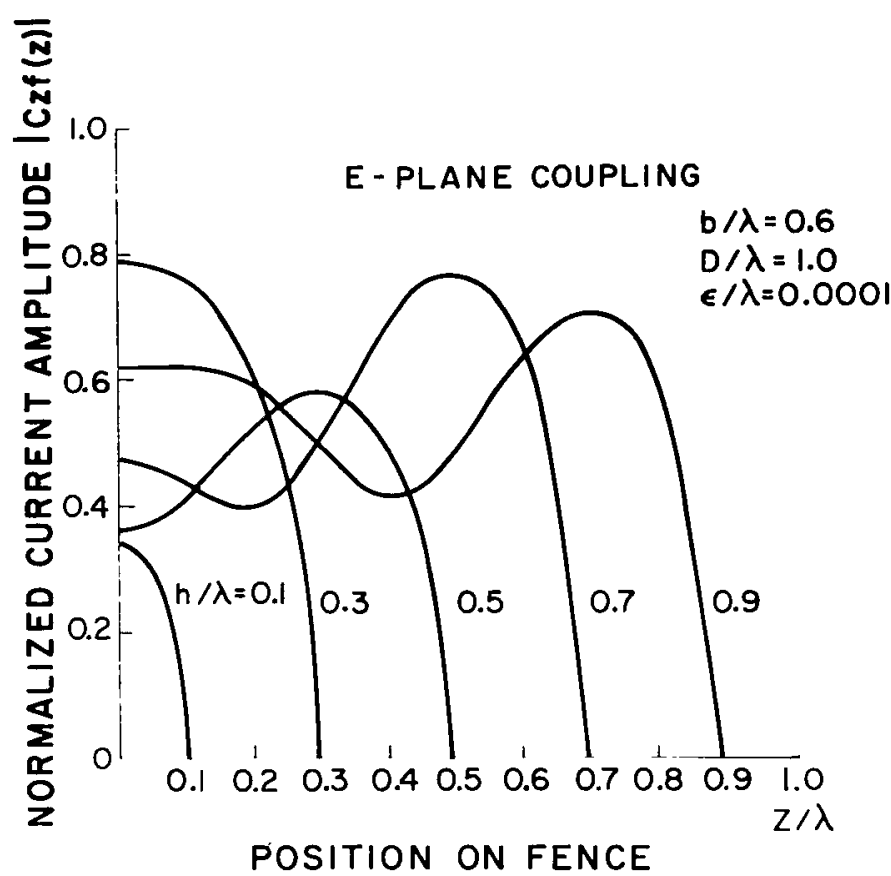

Figure 4.- Fence current distributions for various $\mathrm{h} / \lambda(\mathrm{b} / \lambda=0.2)$

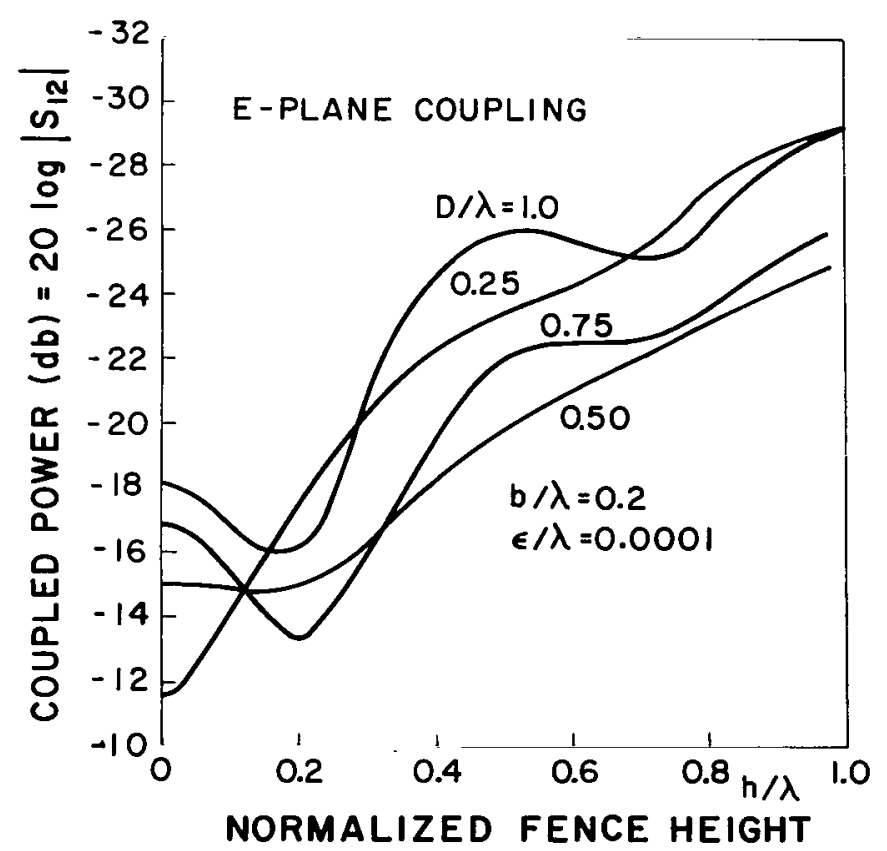

Figure 5.- Theoretical coupled power for E-plane coupling $(\mathrm{b} / \lambda=0.2)$ 


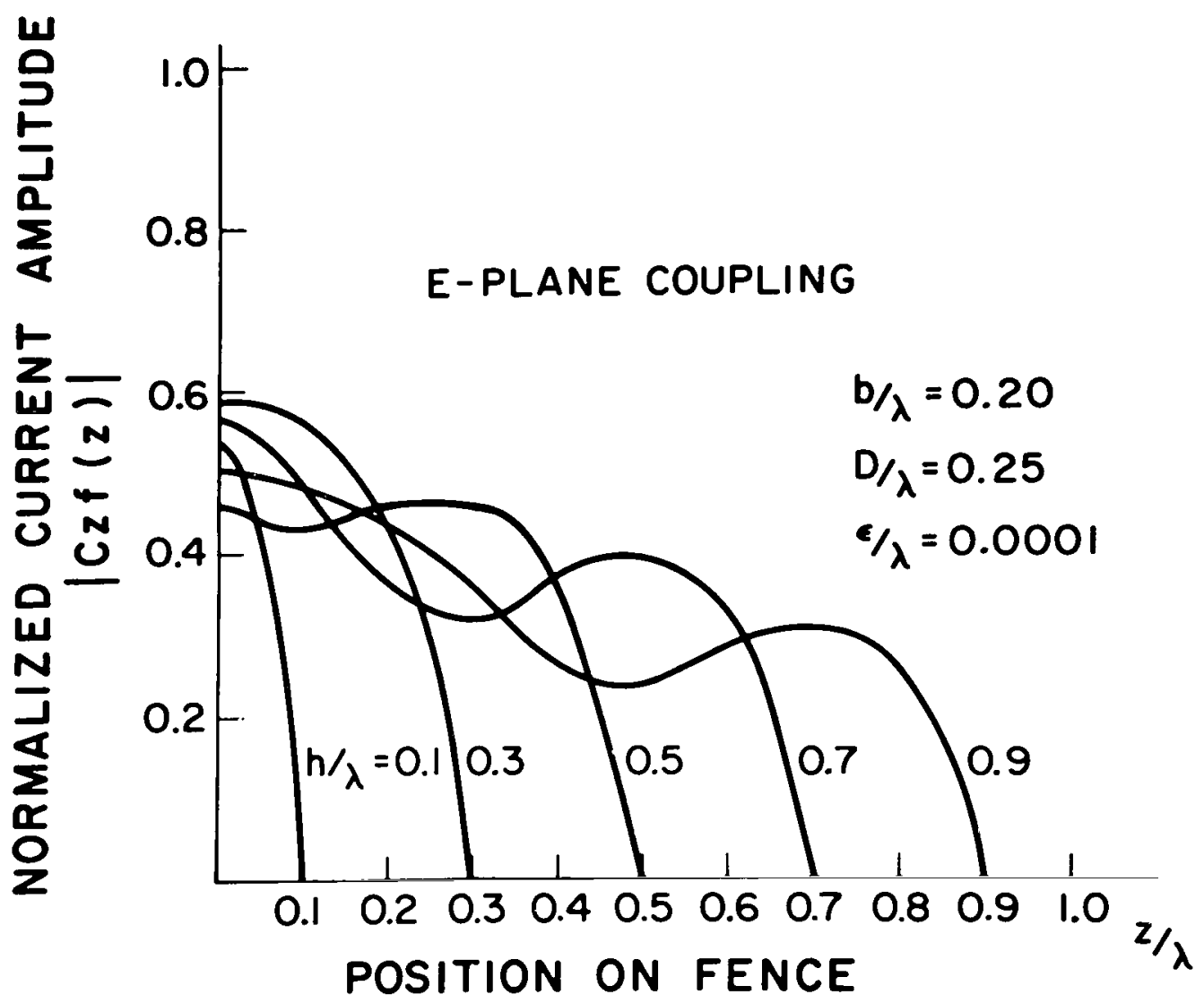

Figure 6.- Fence current distributions for various $\mathrm{h} / \lambda(\mathrm{b} / \lambda=0.2)$

H-Plane Case.- An experiment was conducted to verify the Hplane analytical results. The experiment consisted of mounting two rectangular waveguides with dimensions $0.9 \times 0.4$ inches side by side radiating into a parallel plate structure of spacing 0.4 inches. Because of the image principle this is equivalent to two parallel plate waveguides radiating the dominant TE mode into a half space and with a $D=0.9$ inches. A fence was mounted between the two waveguides and its height was varied. The spacing between the two waveguides was 1.008 inches. (D)

Figure 7 compares these experimental results with the theoretical results. The two curves compare very well although the experiment did indicate a slightly lower value of the coupled power than computed at $h=1$ inch. In addition, some experimental difficulties were encounted in trying to separate out the coupled signal from other reflected signals when the coupling was this small. Figure 8 shows the variation of coupled power as the fence height is varied, and.reveals that generally somewhat greater reductions in coupling can be obtained for the case of H-plane than 
for a comparable E-plane case. After observing the convergence of coupled power with $\mathrm{M}_{\mathrm{T}}$ and $\mathrm{N}_{\mathrm{T}}$, these $\mathrm{H}$-plane results were obtained using $\mathrm{M}_{\mathrm{T}}=3$ and $\mathrm{N}_{\mathrm{T}}=13$. The fence current is nearly singular at the top of the fence and since this distribution is difficult to approximate by a truncated Fourier series there remain small oscillations in the fence current distribution. Since the coupled power depends only on the integral of the current no difficulties were encountered in obtaining convergence of this coupled power computation.

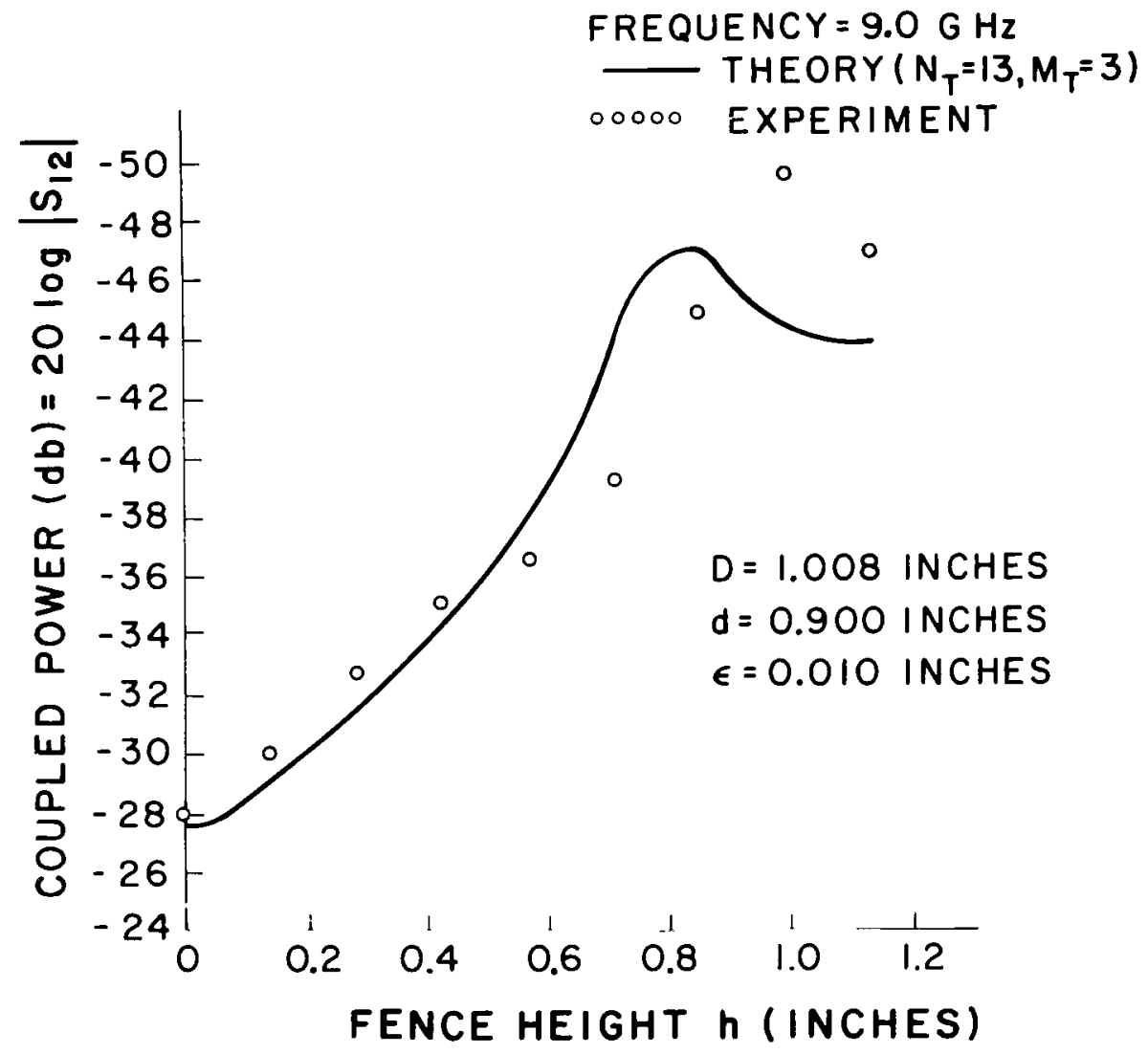

Figure 7.- Experimental and theoretical results for H-plane coupling

Conclusion

This study has shown that under certain conditions the use of metallic fences perpendicular to the ground plane can result in significant decreases in coupled power when placed half-way between parallel plate waveguides. The solutions are rigorous 
under the assumption of a current filament model for the metallic fence, and subject to the use of truncated Fourier series expressions for the fence and aperture distributions.

A comparison is made between the theoretical and experimental results and their agreement is excellent.



NORMALIZED FENCE HEIGHT

Figure 8.- Theoretical coupled power for $\mathrm{H}-\mathrm{plane}$ coupling 


\section{APPENDIX A}

Expressions for the electromagnetic fields in a volume $v^{\prime}$ bounded by a surface $s^{\prime}$ are given by Levine and Schwinger in terms of the tangential electric and magnetic fields on the enclosing surface $s^{\prime}$. The volume $v^{\prime}$ lies in the half space $z \geqq 0$ and a perfectly conducting screen divides space at the plane $z=0$. The end results are given below.

$$
\begin{aligned}
& \bar{E}(\bar{r})=-j \omega \mu \circ \int_{s^{\prime}} \Gamma^{(I)}\left(\bar{r}, \bar{r}^{\prime}\right) \cdot \overline{\mathrm{K}}\left(\bar{r}^{\prime}\right) \mathrm{d} s^{\prime} \\
& -\nabla \times \int_{s^{\prime}} \Gamma^{(2)}\left(\bar{r}, \bar{r}^{\prime}\right) \cdot \overline{\mathrm{K}} \mathrm{m}\left(\bar{r}^{\prime}\right) \mathrm{d} \mathrm{s}^{\prime} \\
& \overline{\mathrm{H}}(\bar{r})=-j \omega \varepsilon \int_{s^{\prime}} \Gamma^{(2)}\left(\bar{r}, \bar{r}^{\prime}\right) \cdot \overline{\mathrm{K} m}\left(\bar{r}^{\prime}\right) \mathrm{d} s^{\prime} \\
& +\nabla \mathrm{x} \int_{s^{\prime}} \Gamma^{(1)}\left(\bar{r}, \bar{r}^{\prime}\right) \cdot \bar{k}\left(\bar{r}^{\prime}\right) \mathrm{d} s^{\prime}
\end{aligned}
$$

The dyadic greens functions $\Gamma^{(1)}$ and $\Gamma^{(2)}$ are chosen to satisfy the boundary conditions at the conducting plane

$$
\left(\left(\hat{z} \times \underline{\Gamma}^{(1)}\left(\bar{x}, \bar{r}^{\prime}\right)\right)=0 \text { and } \hat{z} \times\left(\nabla \times \underline{\Gamma}^{(2)}\left(\bar{r}, \bar{r}^{\prime}\right)\right)=0\right.
$$

for $\bar{r}$ on the conducting plane $z=0$. The surface densities of electric and magnetic current are given by

$$
\begin{aligned}
& \overline{\mathrm{K}}(\bar{r})=\hat{n} \times \mathrm{H}(\bar{r}) \\
& \overline{\mathrm{K}} \mathrm{m}(\overline{\mathrm{r}})=-\hat{n} \times \overline{\mathrm{E}}(\bar{r})
\end{aligned}
$$

where $\hat{\eta}$ is the normal pointing into $s^{\prime}$. The dyadic greens functions are given by Levine and Schwinger (and are easily interpreted in terms of the image principle)

$$
\underline{\Gamma}^{(1),(2)}\left(\bar{r} \cdot \bar{r}^{\prime}\right)=\underline{\Gamma}^{0}\left(\bar{r}, \bar{r}^{\prime}\right) \pm \underline{\Gamma}\left(\bar{r}, \bar{r}^{\prime}-2 \hat{z} \hat{z} \cdot \bar{r}^{\prime}\right) \cdot(\underline{u}-2 \hat{z} \hat{z})
$$


where $\Gamma^{(0)}\left(\bar{x}, \bar{r}^{\prime}\right)$ is the free space dyadic greens function and is written:

$$
\Gamma^{0}\left(r, r^{\prime}\right)=\left(\underline{u}+\frac{1}{k_{0}^{2}} \nabla \nabla\right) G\left(\bar{r}, \bar{r}^{\prime}\right)
$$

where

$$
G\left(\bar{r}, \bar{r}^{\prime}\right)=\frac{e^{-i k} 0\left|\bar{r}-\bar{r}^{\prime}\right|}{4 \pi\left|\bar{r}-\bar{r}^{\prime}\right|}
$$

and

$$
\left|\bar{r}-\bar{r}^{\prime}\right|=\sqrt{\left(x-x^{\prime}\right)^{2}+\left(r-x^{\prime}\right)^{2}+\left(z-z^{\prime}\right)^{2}}
$$

and $\underline{u}$ is the unit dyad.

These equations may be written in a more convenient form using the relation

$$
\nabla \times \Gamma^{(0)}\left(\bar{r}, \bar{r}^{\prime}\right) \cdot \overline{K\left(r^{\prime}\right)}=\nabla G\left(\bar{r}, \bar{r}^{\prime}\right) \times \bar{K}\left(\bar{r}^{\prime}\right)
$$

to obtain:

$$
\begin{aligned}
\bar{E}(\bar{r})= & -j \omega \mu S_{s^{\prime}} \Gamma^{(1)}\left(\bar{r}, \bar{r}^{\prime}\right) \cdot \bar{K}\left(\bar{r}^{\prime}\right) d s^{\prime} \\
& -s_{s^{\prime}} \mathrm{ds}^{\prime}\left[\nabla G\left(\bar{r}, \bar{r}^{\prime}\right) \times \bar{K} m\left(\bar{r}^{\prime}\right)+\nabla G\left(\bar{r}, \bar{r}^{\prime}\right) \times \bar{K}^{I M}\left(\bar{r}, \bar{r}^{\prime}\right)\right]
\end{aligned}
$$

and

$$
\begin{aligned}
H(r)= & -j \omega \varepsilon \int_{s^{\prime}}^{\int} \Gamma^{(2)}\left(r, r^{\prime}\right) \cdot \mathrm{Km}\left(\mathrm{r}^{\prime}\right) \mathrm{d} s^{\prime} \\
& +\int_{s^{\prime}}\left[\nabla G\left(\bar{r}, \bar{r}^{\prime}\right) \times \overline{\mathrm{K}}\left(\bar{r}^{\prime}\right)+\nabla G\left(\bar{r}, \bar{r}^{\prime \prime}\right) \times \overline{\mathrm{K}}^{\mathrm{IM}}(\bar{r})\right] \mathrm{d} s^{\prime}
\end{aligned}
$$

where

$$
\overline{\mathrm{K}}^{\mathrm{IM}}\left(\overline{\mathrm{r}}^{\prime}\right)=\overline{\mathrm{K}}\left(\overline{\mathrm{r}}^{\prime}\right) \cdot(\underline{U}-2 \hat{\mathrm{x}} \hat{\mathrm{X}}-2 \hat{\mathrm{Y}} \hat{y})
$$


and

$$
\overline{\mathrm{K}}_{\mathrm{m}}^{\mathrm{IM}}\left(\overline{\mathrm{r}}^{\prime}\right)=\overline{\mathrm{K}}_{\mathrm{m}}\left(\overline{\mathrm{r}}^{\prime}\right) \cdot(\underline{\mathrm{U}}-2 \hat{\mathrm{z}} \hat{\mathrm{z}})
$$

and

$$
\begin{aligned}
\left|\bar{r}-\bar{r}^{\prime \prime}\right| & =\left|\bar{r}-\left(\bar{r}^{\prime}-2 \hat{z} \hat{z} \cdot \bar{r}^{\prime}\right)\right| \\
& =\sqrt{\left(x-x^{\prime}\right)^{2}+\left(y-y^{\prime}\right)^{2}+\left(z+z^{\prime}\right)^{2}}
\end{aligned}
$$

These relations are in a form which allow interpretation in terms of conventional potential functions. In doing this, it is convenient to restrict the formulation immediately to the case in point; wherein apertures are cut into the ground plane. When this is done, the contributions from the electric current on the ground plane vanish because of the form of the Greens Functions and the only electric current contributions which remain are due to the integrals over the fence and its image. The magnetic current contributions arise from the tangential electric field in the apertures where the magnetic current and its image current add in phase. One may therefore define the following potential functions for the half plane $z \geqq 0$.

$$
\overline{\Pi m}(\bar{r})=\frac{j}{2 \pi \omega} \sum_{p} \int_{\operatorname{Sp}}\left(\hat{z} \times E\left(\bar{r}^{\prime}\right)\right) \frac{e^{-j k_{0}\left|\bar{r}-\bar{r}^{\prime}\right|}}{\left|\bar{r}-\bar{r}^{\prime}\right|} \mathrm{dSp}{ }^{\prime}
$$

where

$$
\left|\bar{r}-\bar{r}^{\prime}\right|=\sqrt{z^{2}+\left(x-x^{\prime}\right)^{2}+\left(y-y^{\prime}\right)^{2}}
$$

and

$$
\begin{aligned}
\overline{\mathrm{A}}(\bar{r})=\frac{1}{4 \pi v_{0}} & \left\{\int_{\operatorname{Sf}}\left[\hat{r} \times \overline{\mathrm{H}}\left(\bar{r}^{\prime}\right) \frac{e^{-i k_{0}\left|\bar{r}-\bar{r}^{\prime}\right|}}{\left|\bar{r}-\bar{r}^{\prime}\right|}\right]\right. \\
& \left.+\int_{i m}\left[\hat{n} \times \overline{\mathrm{H}}^{I M}\left(\bar{r}^{\prime \prime}\right) \frac{e^{-i k_{0}\left|\bar{r}-\bar{r}^{\prime \prime}\right|}}{\left|\bar{r}-\bar{r}^{\prime \prime}\right|}\right] d s_{i m}\right\}
\end{aligned}
$$


The first of these is the conventional Hertzian magnetic potential and the second is a Hertzian electric potential more commonly known as the vector potential. In the latter case, the integrals are performed over the entire surface of the fence plus its image. For thin fences, it is convenient to assume that the entire current is concentrated at the center of the fence along a filamentary ribbon. When this is done the vector potential may be written in terms of the line integral over the total fence current.

$$
\begin{aligned}
\bar{A}(\bar{r})=\frac{1}{4 \pi v_{0}} & \left\{\int_{\ell f} \bar{J}\left(r^{\prime}\right) \frac{e^{-i k_{0}\left|\bar{r}-\bar{r}^{\prime}\right|}}{\left|\bar{r}-\bar{r}^{\prime}\right|} d \ell F\right. \\
& \left.+\int_{\ell i m} \bar{J}^{I M}\left(\bar{r}^{\prime \prime}\right) \frac{e^{-i k_{0}\left|\bar{r}-\bar{r}^{\prime}\right|}}{\left|\bar{r}-\bar{r}^{\prime \prime}\right|} \text { d } l i m\right\}
\end{aligned}
$$

Using these definitions the half space electromagnetic field is written:

$$
\begin{aligned}
& \bar{E}(\bar{r})=\frac{-j \omega}{k_{0}^{2}}\left[\nabla(\nabla \cdot \bar{A})+k_{0}^{2} \bar{A}\right]-j \omega \nabla x \bar{\Pi} m \\
& \bar{B}(\bar{r})=\nabla x \bar{A}+\nabla(\nabla \bar{\Pi} m)+k_{0}^{2} \bar{\Pi} m
\end{aligned}
$$

The above are valid for the general three dimensional fence/ aperture problems, but since the cases considered in this report are only two dimensional, the following integral relation is used to derive the appropriate two dimensional equations.

$$
\int_{-\infty}^{\infty} \frac{e^{-i k_{0} \sqrt{n_{1}{ }^{2}+\eta_{2}{ }^{2}+\left(x-x^{\prime}\right)^{2}}}}{\sqrt{n_{1}{ }^{2} n_{2}{ }^{2}+\left(x-x^{\prime}\right)^{2}}} d x^{\prime}=-i \pi H_{0}(2)\left(k \sqrt{\eta_{1}{ }^{2}+\eta_{2}{ }^{2}}\right)
$$


REFERENCES

1. Hannan, P. W.; Lerner, D. S.; and Knittel, G. H.: Impedance Matching a Phased-Array Antenna over Wide Scan Angles by Connecting Circuits. IEEE Transactions on Antennas and Propagation, Vol. AP-13, No. 1, January 1965, pp. 28-34.

2. Magill, E. G.; and Wheeler, H. A.: Wide Angle Impedance Matching of a Planar Array Antenna by a Dielectric Sheet. IEEE Transactions on Antennas and Propagation, AP-14, January 1966 , pp. 49-53.

3. Wong, N. S. et al: Investigation of Use of Superimposed Surface Wave Modes. AD-631 936, Final Report on Contract AF 19(628) - 4984, Technical Report, AFCRI-66-200-1, February 28, 1966 .

4. Amitay, N.: Improvement of Planar Array Match by Compensation through Contiguous Element Coupling. IEEE Transactions on Antennas and Propagation, Vol. AP-14, No. 5, September 1966, pp. 580-585.

5. Lee, S. W.: Impedance Matching of an Infinite Phased Array by Dielectric Sheets. Electronics Letters 2, October 1966, pp. 366-368.

6. Galindo, V.; and Wu, C. P.: Dielectric Loaded and Covered Rectangular Waveguide Phased Array. International Symposium on Antennas and Propagation, Palo Alto, California, December 1966 .

7. Amitay, N.; Butzien, P. E.; and Heidt, R. C.: Match Optimization of a Two-Port Phased Array Antenna Element. IEEE Transactions on Antennas and Propagation, Vol. AP-16, No. 1, January 1968, pp. 47-57.

8. Wu, C. P.; and Galindo, V.: Surface-Wave Effects on Dielectric Sheathed Phased Arrays of Rectangular Waveguides. The Bell System Technical Journal, January 1968, pp. 117-142.

9. Hannan, P. W.; and Litt, S. P.: Capacitive Ground Plane for a Phased Array Antenna. 1968 IEEE Professional Group on Antennas and Propagation, International Symposium, September 9, 1968 .

10. Edelberg, S.; and Oliner, A. A.: Mutual Coupling Effects in Large Antenna Arrays II: Compensation Effects. IRE Transactions on Antennas and Propagation, Vol. AP-8, July 1960, pp. 360-367.

11. Brennecke, N. R.; and Moule, W. N.: Use of Fences to Optimize Operating Impedance of Phase Arrays, Using an Improved Measuring Technique. PTGAP International Symposium Digest, September 21, 1964, pp. 134-142. 
12. Dufort, E. C.: Design of Corrugated Plates for Phased Array Matching. IEEE Transactions on Antennas and Propagation, Vol. AP-16, No. 1, January 1968, pp. 37-46.

13. Allen, C. C.: Mutual Coupling Effects in Phased Array Antennas. Thirteenth Annual Symposium, USAF Antenna Research and Development Program, University of Illinois, October 14, 1963.

14. Mailloux, R. J.: Radiation and Hear-Field Coupling Between Two Collinear Open-Ended Waveguides. IEEE Transactions on Antennas and Propagation, Vol. AP-17, No. 1, January 1969, pp. 49-55.

15. Wu, C. P.: Numerical Solutions for the Coupling Between Waveguides in Finite Arrays. Radio Science, Vol. 4, No. 3, March 1969, pp. 245-254. 


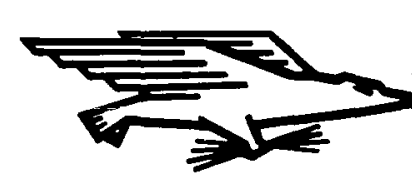

POSTAGE AND FEES PAID NATIONAL AERONAUTICS AND SPACE ADMINISTRATION
O5U OOI $32 \quad 51305 \quad 7107000903$
AIR FORCE WEAPONS LABORATORY/WLOL/
KIRTLAND AFB, NEW MEXICO 87117

ATT E. LOU BOWMAN, CHIEF, TECH. LIBRARY $\begin{array}{ll}\text { POSTMASTER: } & \begin{array}{l}\text { If Undeliverable (Section } 158 \\ \text { Postal Manual) Do Not Return }\end{array}\end{array}$

"The aeronautical and space activities of the United States sball be conducted so as to contribute . . to the expansion of buman knowledge of phenomena in the atmosphere and space. The Administration shall provide for the widest practicable and appropriate dissemination of information concerning its activities and the results thereof."

- National Aeronautics and Space ACt of 1958

\section{NASA SCIENTIFIC AND TECHNICAL PUBLICATIONS}

TECHNICAL REPORTS: Scientific and technical information considered important, complete, and a lasting contribution to existing knowledge.

TECHNICAL NOTES: Information less broad in scope but nevertheless of importance as a contribution to existing knowledge.

\section{TECHNICAL MEMORANDUMS:}

Information receiving limited distribution because of preliminary data, security classification, or other reasons.

CONTRACTOR REPORTS: Scientific and technical information generated under a NASA contract or grant and considered an important contribution to existing knowledge.
TECHNICAL TRANSLATIONS: Information published in a foreign language considered to merit NASA distribution in English.

SPECIAL PUBLICATIONS: Information derived from or of value to NASA activities. Publications include conference proceedings, monographs, data compilations, handbooks, sourcebooks, and special bibliographies.

\section{TECHNOLOGY UTILIZATION}

PUBLICATIONS: Information on technology used by NASA that may be of particular interest in commercial and other non-aerospace applications. Publications include Tech Briefs, Technology Utilization Reports and Technology Surveys.

Details on the availability of these publications may be obtained from:

SCIENTIFIC AND TECHNICAL INFORMATION OFFICE

NATIONAL AERONAUTICS AND SPACE ADMINISTRATION Washington, D.C. 20546 